\title{
Analytical solution for undrained plane strain expansion of a cylindrical cavity in modified cam clay
}

\author{
Vincenzo Silvestri* and Ghassan Abou-Samra \\ Department of Civil, Geological, and Mining Engineering, Ecole Polytechnique, P. B. 6079, \\ Station Centre-Ville, Montreal, Quebec, Canada H3C $3 A 7$
}

(Received March 23, 2011, Revised November 23, 2011, Accepted December 28, 2011)

\begin{abstract}
This paper presents the results of analytical and numerical analyses of the effects of performing a pressuremeter test or driving a pile in clay. The geometry of the problem has been simplified by the assumptions of plane strain and axial symmetry. Pressuremeter testing or installation of driven piles has been modelled as an undrained expansion of a cylindrical cavity. Stresses, pore water pressures, and deformations are found by assuming that the clay behaves like normally consolidated modified Cam clay. Closed-form solutions are obtained which allow the determination of the principal effective stresses and the strains around the cavity. The analysis which indicates that the intermediate principal stress at critical state is not equal to the mean of the other two principal stresses, except when the clay is initially isotropically consolidated, also permits finding the limit expansion and excess pore water pressures by means of the Almansi finite strain approach. Results are compared with published data which were determined using finite element and finite difference methods.
\end{abstract}

Keywords: undrained cylindrical expansion; plane strain; modified Cam clay; stress-strain curves; analytical and numerical analyses; comparisons.

\section{Introduction}

The undrained expansion of spherical and cylindrical cavities in a clay deposit is a problem that is of interest to geotechnical engineers. Solutions to this problem have been obtained for a number of ideal materials and these have been used to model cone penetration tests and pressuremeter tests, and the installation of driven piles (Carter et al. 1979, Yu 2000). Hill (1950) has presented a comprehensive finite (natural, logarithmic, or true) strain solution of stresses and displacements for the expansion of spherical and cylindrical cavities in a Tresca material. Yu (2000) expanded Hill's solution and showed that his result was valid for any value of Poisson's ratio, and therefore, for Tresca material, was more general than that of Gibson and Anderson (1961). In addition, Yu (2000) presented an exhaustive review of spherical and cylindrical cavity solutions. Palmer (1972) showed that the result of a single pressuremeter test in clay was sufficient to determine a complete stressstrain relation in plane strain. The only restrictive assumption necessary was that the deformation is under undrained condition; there was no restriction to infinitesimal strains or to simple elastic

*Correspohor, Professor, E-mail: vincenzo.silvestri@polymtl.ca 
perfectly plastic soils. Similar solutions were presented by Baguelin et al. (1972) and Ladanyi (1972).

The assumptions of plane strain in the vertical direction and axially symmetrical deformation considerably simplify the analysis of the expansion of a long cylindrical cavity. However, as more complex models are used to represent the soil, then the more remote becomes the possibility of obtaining closed-form solutions (Carter et al. 1979, Wood 2007). For example, the problem of the expansion of spherical and cylindrical cavities in modified Cam clay was approached up to recently, by using numerical methods, since it was thought that closed-form solutions could not be obtained (Yu 2000). However, Silvestri and Abou-Samra (2011) determined a finite strain closed-form solution for the expansion of a spherical cavity in modified Cam clay.

In the spherically symmetrical problem both the shape of the plastic boundary and the strain path are determined by symmetry alone (Hill 1950). In the special problem of the expansion of long cylindrical cavities, that is the subject of the present paper, only the shape of the plastic boundary is known before hand. The strain path for every individual particle has to be calculated, along with the stresses, step by step as the cylindrical cavity expands (Hill et al. 1947, Hill 1950).

In this paper, a method is presented which may be employed whenever the soil can be modelled using modified Cam clay. The first part of the paper presents existing closed-form solutions of the stress-strain relationships of modified Cam clay sheared undrained. The second part gives analytical expressions for the principal effective stresses generated during shearing in plane strain and undrained conditions. The third part presents the stresses, pore water pressures, and deformations that occur around an expanding cylindrical cavity. The analysis is applied to an example presented by Carter et al. (1979) and Randolph et al. (1979). Comparisons are made with both the elastic perfectly plastic solution of Gibson and Anderson (1961) and numerical results which were obtained by means of the finite element (Carter et al. 1979) and finite difference (Itasca 1995) methods.

\section{Modified Cam clay}

\subsection{Soil model}

Only a brief introduction of the modified Cam clay model is presented in this paper. Interested readers may refer to the textbook by Wood (2007) for an in-depth treatment. The Cam clay model requires the specification of five parameters, and values for all of them may be obtained from standard laboratory tests. These parameters are

$\lambda=$ the slope of the isotropic virgin consolidation line in $v-\ln p^{\prime}$ space;

$\kappa=$ the slope of the isotropic swelling line in $v-\ln p^{\prime}$ space;

$\Gamma=$ the value of the specific volume for $p^{\prime}=1 \mathrm{kPa}$ on the critical state line in $v-\ln p^{\prime}$ space;

$M=$ the slope of the stress ratio $q / p^{\prime}$ at critical state; $M=6 \sin \phi^{\prime}\left(3-\sin \phi^{\prime}\right)$, with

$\phi^{\prime}=$ friction angle of clay; and

$G^{\prime}=$ the elastic shear modulus.

In the above, $v$ is the specific volume, and the mean effective stress $p^{\prime}$ and the deviator stress $q$ are given by

$$
p^{\prime}=\left(\sigma_{1}{ }^{\prime}+\sigma_{2}{ }^{\prime}+\sigma_{3}{ }^{\prime}\right) / 3
$$


Analytical solution for undrained plane strain expansion of a cylindrical cavity in modified cam clay 21

$$
q=\frac{1}{\sqrt{2}}\left[\left(\sigma_{1}{ }^{\prime}-\sigma_{2}{ }^{\prime}\right)^{2}+\left(\sigma_{2}{ }^{\prime}-{\sigma_{3}}^{\prime}\right)^{2}+\left(\sigma_{3}{ }^{\prime}-{\sigma_{1}}^{\prime}\right)^{2}\right]^{1 / 2}
$$

where $\sigma_{1}{ }^{\prime}, \sigma_{2}{ }^{\prime}, \sigma_{3}{ }^{\prime}$ are the effective principal stresses. In addition to the above-listed parameters, a full description of the soil requires the knowledge of the initial in situ stresses. For stress levels within the yield surface, deformations are governed by the elastic bulk modulus $K^{\prime}=v p^{\prime} / \kappa$ and the shear modulus $G^{\prime}=3\left(1-2 v^{\prime}\right) K^{\prime} / 2\left(1+v^{\prime}\right)$, where $v^{\prime}=$ Poisson's ratio of soil skeleton. Yielding occurs whenever the stresses obey the following criterion

$$
f=q^{2}-M^{2} p^{\prime}\left(p_{c}{ }^{\prime}-p^{\prime}\right)=0
$$

where $p_{c}{ }^{\prime}$ is a hardening parameter which defines the intersection of the current ellipsoidal yield locus and the $p^{\prime}$ axis. As the material yields and hardens, plastic flow is determined by an associated flow rule. Fig. 1 illustrates the essential features of the model. An effective stress path (ESP) obtained from a consolidated undrained triaxial test is also shown in this figure. The test begins at point $\mathrm{A}\left(p_{i}{ }^{\prime}=\left(1+2 K_{0}\right) \sigma_{z i}{ }^{\prime} / 3, q_{i}=\left(1-K_{0}\right) \sigma_{z i}{ }^{\prime}\right)$ and ends at point $\mathrm{B}\left(p_{f}{ }^{\prime}=2^{-\Lambda} p_{0}{ }^{\prime}, q_{f}=M p_{f}{ }^{\prime}\right)$, where $K_{0}$ is the coefficient of lateral earth pressure at rest, $\sigma_{z i}{ }^{\prime}$ is the initial in situ vertical effective stress, $\Lambda=(\lambda-\kappa) / \lambda$, and $p_{0}{ }^{\prime}$ defines the intersection of the effective stress path and the $p^{\prime}$ axis The equation of the effective stress path is

$$
\frac{q}{p^{\prime}}=\eta=\left[\left(\frac{p_{i}^{\prime}}{p^{\prime}}\right)^{1 / \Lambda}\left(M^{2}+\eta_{i}^{2}\right)-M^{2}\right]^{1 / 2}, p^{\prime} \leq p_{i}^{\prime}
$$

in which $\eta_{i}=$ in situ stress ratio $q_{i} / p_{i}{ }^{\prime}=3\left(1-K_{0}\right) /\left(1+2 K_{0}\right)$. This equation may be also written as

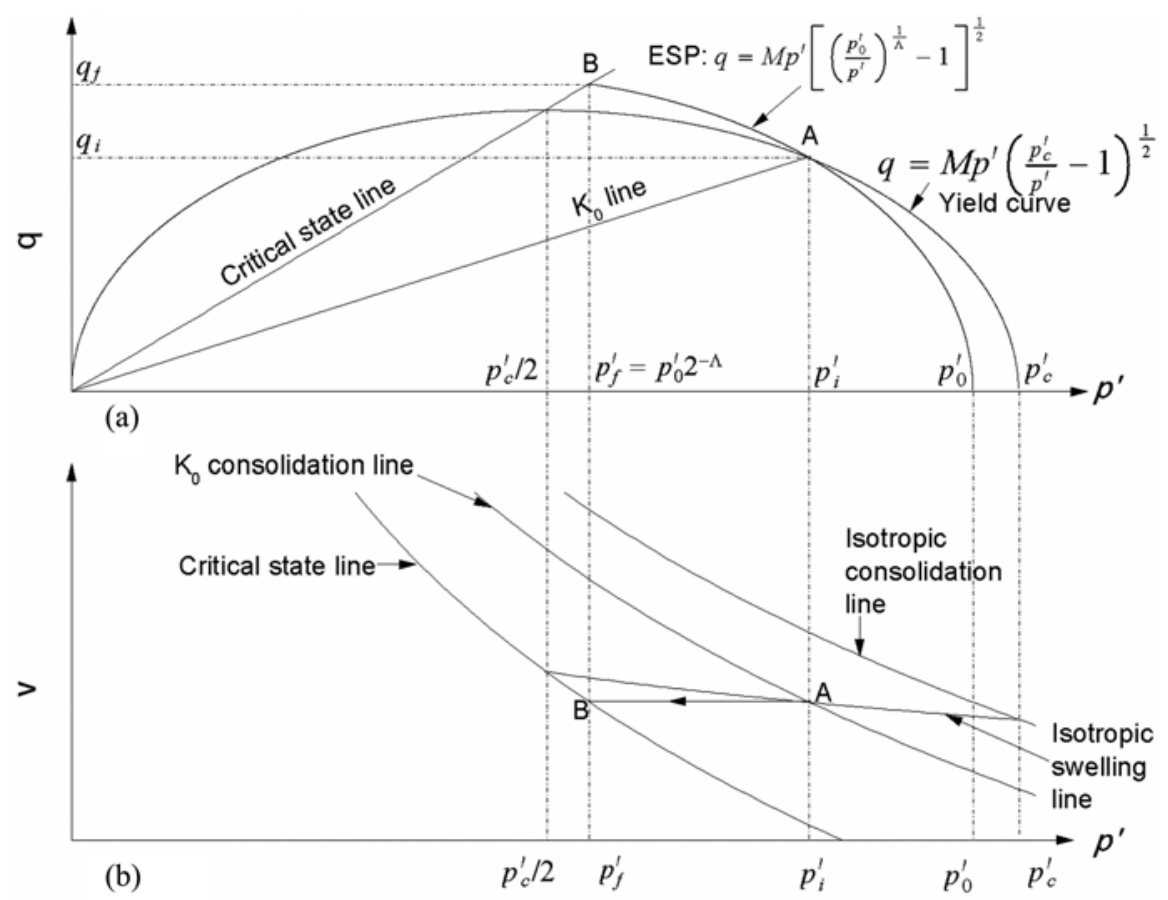

Fig. 1 Modified Cam clay model 


$$
\frac{q}{p^{\prime}}=\eta=M\left[\left(\frac{p_{o}{ }^{\prime}}{p^{\prime}}\right)^{1 / \Lambda}-1\right]^{1 / 2}, p^{\prime} \leq p_{i}{ }^{\prime}
$$

The Cam clay yield and effective stress path surfaces are assumed to be formed by rotation about the mean effective stress axis (or space diagonal $\sigma_{1}{ }^{\prime}=\sigma_{2}{ }^{\prime}=\sigma_{3}{ }^{\prime}$ ) and sections through these surfaces at constant mean effective stress $p^{\prime}$ are consequently circles. It is assumed that although failure can be better approximated by a Mohr-Coulomb criterion with constant friction angle $\phi^{\prime}$, than by a von Mises criterion, both pre-failure and failure responses are considered to be governed by the Cam clay expanding surfaces.

\subsection{Deviator stress-strain relationships of modified Cam clay}

Perić and Ayari (2002) obtained the deviatoric stress-strain relationship of normally consolidated Cam clay sheared undrained by combining the elastic and plastic strain components. For constant Poisson's ratio, their expression reads

$$
\begin{aligned}
\varepsilon_{q}= & \frac{2}{9}\left(\frac{1+v^{\prime}}{1-2 v^{\prime}}\right) \frac{k}{v}\left\{\left(\eta-\eta_{i}\right)(1-2 \Lambda)-2 \Lambda M\left[\tan ^{-1}\left(\frac{\eta}{M}\right)-\tan ^{-1}\left(\frac{\eta_{i}}{M}\right)\right]\right\} \\
& +\frac{2 k \Lambda}{v M}\left\{\tanh ^{-1}\left(\frac{\eta}{M}\right)-\tanh ^{-1}\left(\frac{\eta_{i}}{M}\right)-\left[\tan ^{-1}\left(\frac{\eta}{M}\right)-\tan ^{-1}\left(\frac{\eta_{i}}{M}\right)\right]\right\}
\end{aligned}
$$

where $\varepsilon_{q}=$ deviatoric strain $=\sqrt{2} / 3\left[\left(\varepsilon_{1}-\varepsilon_{2}\right)^{2}+\left(\varepsilon_{2}-\varepsilon_{3}\right)^{2}+\left(\varepsilon_{3}-\varepsilon_{1}\right)^{2}\right]^{1 / 2}$, and $\varepsilon_{1}, \varepsilon_{2}, \varepsilon_{3}$ are the finite (natural, logarithmic, or true) principal strains.

Silvestri and Abou-Samra (2009) also obtained stress-strain relationships for normally consolidated Cam clay sheared undrained for $\eta_{i}=0$ and for both constant Poisson's ratio $v^{\prime}$ and constant shear modulus $G^{\prime}$. Their expression for constant shear modulus $G^{\prime}$ becomes

$$
\varepsilon_{q}=\frac{q-q_{i}}{3 G^{\prime}}+\frac{2 k \Lambda}{v M}\left\{\tanh ^{-1}\left(\frac{\eta}{M}\right)-\tanh ^{-1}\left(\frac{\eta_{i}}{M}\right)-\left[\tan ^{-1}\left(\frac{\eta}{M}\right)-\tan ^{-1}\left(\frac{\eta_{i}}{M}\right)\right]\right\}
$$

for the general case of $\eta_{i} \neq 0$.

Regarding the choice of the shear modulus $G^{\prime}$, the use of a constant value (i.e., Eq. (6)) results in a conservative model (Carter et al. 1979).

\section{Theoretical considerations}

\subsection{Axially symmetrical stresses and deformations around the cylindrical cavity}

The effective stress path in $q-p^{\prime}$ space is described by Eqs. (4). However, each principal effective stress cannot be found in general from the expressions in Eqs. (4). In order to determine these stresses, it is convenient to consider cylindrical coordinates $r, \theta, z$. Let the total principal stresses in the radial, tangential, and axial (vertical) directions in the medium surrounding the cavity be denoted by $\sigma_{r}, \sigma_{\theta}, \sigma_{z}$, the corresponding effective stresses by $\sigma_{r}{ }^{\prime}, \sigma_{\theta}{ }^{\prime}, \sigma_{z}{ }^{\prime}$, and the finite (natural) strains in the same directions by $\varepsilon_{r}, \varepsilon_{\theta}, \varepsilon_{z}$. Fig. 2 presents the idealized geometry and the stresses 


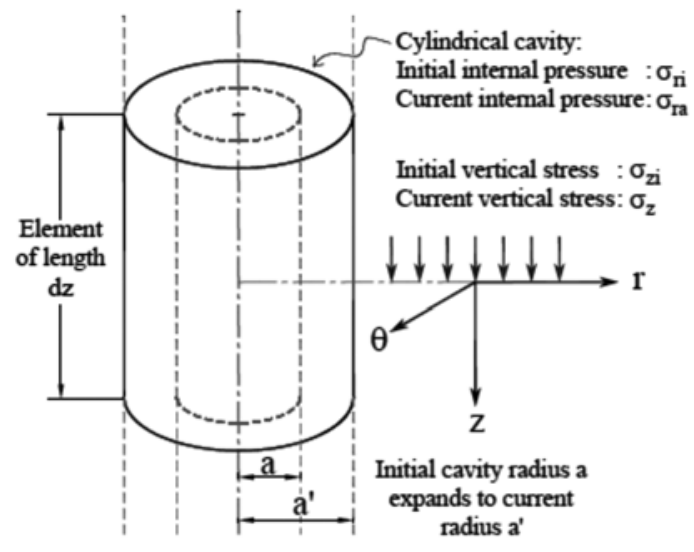

(a) Cylindrical cavity

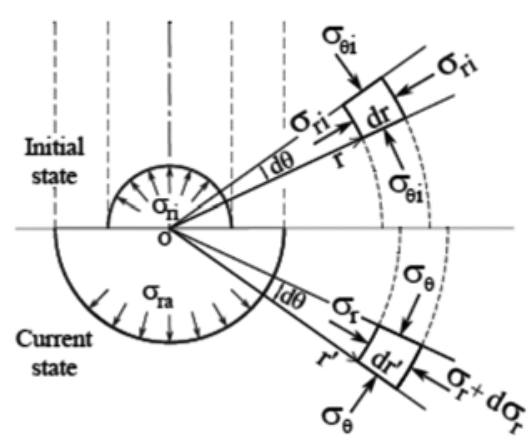

(b) Horizontal plane

Fig. 2 Initial and current conditions around cylindrical cavity

acting in the soil around the cylindrical cavity. The initial total stresses are $\sigma_{r i}=\sigma_{\theta i}$ and $\sigma_{z i}$. The corresponding initial effective stresses are $\sigma_{r i}{ }^{\prime}=\sigma_{\theta i}{ }^{\prime}=K_{0} \sigma_{z i}{ }^{\prime}$ and $\sigma_{z i}{ }^{\prime}$. The total principal strain increments $d \varepsilon_{r}, d \varepsilon_{\theta}, d \varepsilon_{z}$ are given by the following expressions in the case of modified Cam clay

$$
\begin{aligned}
& d \varepsilon_{r}=\frac{1}{2 G^{\prime}\left(1+v^{\prime}\right)}\left[d \sigma_{r}{ }^{\prime}-v^{\prime}\left(d \sigma_{\theta}{ }^{\prime}+d \sigma_{z}{ }^{\prime}\right)\right]+d \beta\left[\frac{M^{2}}{3}\left(2 p^{\prime}-p_{c}{ }^{\prime}\right)+3 S_{r}\right] \\
& d \varepsilon_{\theta}=\frac{1}{2 G^{\prime}\left(1+v^{\prime}\right)}\left[d \sigma_{\theta}{ }^{\prime}-v^{\prime}\left(d \sigma_{z}{ }^{\prime}+d \sigma_{r}{ }^{\prime}\right)\right]+d \beta\left[\frac{M^{2}}{3}\left(2 p^{\prime}-p_{c}{ }^{\prime}\right)+3 S_{\theta}\right] \\
& d \varepsilon_{z}=\frac{1}{2 G^{\prime}\left(1+v^{\prime}\right)}\left[d \sigma_{z}{ }^{\prime}-v^{\prime}\left(d \sigma_{r}{ }^{\prime}+d \sigma_{\theta}{ }^{\prime}\right)\right]+d \beta\left[\frac{M^{2}}{3}\left(2 p^{\prime}-p_{c}{ }^{\prime}\right)+3 S_{z}\right]
\end{aligned}
$$

where $d \beta$ is a nonnegative proportionality factor, and $S_{r}=\sigma_{r}{ }^{\prime}-p^{\prime}, S_{\theta}=\sigma_{\theta}{ }^{\prime}-p^{\prime}, S_{z}=\sigma_{z}^{\prime}-p^{\prime}$ are the deviator stresses. In addition, while the first term on the right-hand side of each equation represents the elastic strain increment, the second term refers to the plastic strain increment. The plastic strain increment components $d \varepsilon_{i j}^{p}$ are found from the associated flow rule (Mendelson 1968)

$$
d \varepsilon_{i j}^{p}=\frac{\partial g}{\partial \sigma_{i j}{ }^{\prime}} d \beta
$$

where $g$ is the plastic potential which is equal to the yield function $f$ in Eq. (3) and $\sigma_{i j}{ }^{\prime}$ is the effective stress tensor.

The principal effective stress increments $d \sigma_{r}{ }^{\prime}, d \sigma_{\theta}{ }^{\prime}$, are found directly from Eqs. (7), yielding

$$
\begin{aligned}
& d \sigma_{r}{ }^{\prime}=\frac{2 G^{\prime}}{1-2 v^{\prime}}\left[\left(1-v^{\prime}\right) d \varepsilon_{r}+v^{\prime}\left(d \varepsilon_{\theta}+d \varepsilon_{z}\right)\right]-d \beta\left[K^{\prime} M^{2}\left(2 p^{\prime}-p_{c}{ }^{\prime}\right)+6 G^{\prime} S_{r}\right] \\
& d \sigma_{\theta}{ }^{\prime}=\frac{2 G^{\prime}}{1-2 v^{\prime}}\left[\left(1-v^{\prime}\right) d \varepsilon_{\theta}+v^{\prime}\left(d \varepsilon_{z}+d \varepsilon_{r}\right)\right]-d \beta\left[K^{\prime} M^{2}\left(2 p^{\prime}-p_{c}{ }^{\prime}\right)+6 G^{\prime} S_{\theta}\right] \\
& d \sigma_{z}{ }^{\prime}=\frac{2 G^{\prime}}{1-2 v^{\prime}}\left[\left(1-v^{\prime}\right) d \varepsilon_{z}+v^{\prime}\left(d \varepsilon_{r}+d \varepsilon_{\theta}\right)\right]-d \beta\left[K^{\prime} M^{2}\left(2 p^{\prime}-p_{c}{ }^{\prime}\right)+6 G^{\prime} S_{z}\right]
\end{aligned}
$$


where the bulk modulus $K^{\prime}=2 G^{\prime}\left(1+v^{\prime}\right) / 3\left(1-2 v^{\prime}\right)$.

The expansion takes place in plane strain in the vertical direction (i.e., $d \varepsilon_{z}=0$ ) and in undrained conditions (i.e., $d \varepsilon_{r}+d \varepsilon_{\theta}=0$ or $d \varepsilon_{r}=-d \varepsilon_{\theta}$ ). As a result, Eqs. (9) become

$$
\begin{aligned}
& d \sigma_{r}{ }^{\prime}=-2 G^{\prime} d \varepsilon_{\theta}-d \beta\left[K^{\prime} M^{2}\left(2 p^{\prime}-p_{c}{ }^{\prime}\right)+6 G^{\prime} S_{r}\right] \\
& d \sigma_{\theta}{ }^{\prime}=2 G^{\prime} d \varepsilon_{\theta}-d \beta\left[K^{\prime} M^{2}\left(2 p^{\prime}-p_{c}{ }^{\prime}\right)+6 G^{\prime} S_{\theta}\right] \\
& d \sigma_{z}^{\prime}=-d \beta\left[K^{\prime} M^{2}\left(2 p^{\prime}-p_{c}{ }^{\prime}\right)+6 G^{\prime} S_{z}\right]
\end{aligned}
$$

The proportionality factor $d \beta$ is found by adding Eqs. (10) together, yielding

$$
d \sigma_{r}{ }^{\prime}+d \sigma_{\theta}{ }^{\prime}+d \sigma_{z}{ }^{\prime}=3 d p^{\prime}=-3 d \beta\left[K^{\prime} M^{2}\left(2 p^{\prime}-p_{c}{ }^{\prime}\right)\right]
$$

because $d \varepsilon_{r}=-d \varepsilon_{\theta}$, resulting in

$$
d \beta=-\frac{d p^{\prime}}{K^{\prime} M^{2}\left(2 p^{\prime}-p_{c}^{\prime}\right)}
$$

Substitution of this expression into Eqs. (10) leads to

$$
\begin{aligned}
& d \sigma_{r}{ }^{\prime}=-2 G^{\prime} d \varepsilon_{\theta}+d p^{\prime}\left[1+\frac{6 G^{\prime} S_{r}}{K^{\prime} M^{2}\left(2 p^{\prime}-p_{c}{ }^{\prime}\right)}\right] \\
& d \sigma_{\theta}{ }^{\prime}=2 G^{\prime} d \varepsilon_{\theta}+d p^{\prime}\left[1+\frac{6 G^{\prime} S_{\theta}}{K^{\prime} M^{2}\left(2 p^{\prime}-p_{c}{ }^{\prime}\right)}\right] \\
& d \sigma_{z}{ }^{\prime}=d p^{\prime}\left[1+\frac{6 G^{\prime} S_{z}}{K^{\prime} M^{2}\left(2 p^{\prime}-p_{c}{ }^{\prime}\right)}\right]
\end{aligned}
$$

The vertical effective stress is found from Eq. (13c). Rearrangement of this equation gives

$$
d \sigma_{z}{ }^{\prime}-d p^{\prime}=\frac{6 G^{\prime} S_{z} d p^{\prime}}{K^{\prime} M^{2}\left(2 p^{\prime}-p_{c}{ }^{\prime}\right)}
$$

But, since $d \sigma_{z}^{\prime}-d p^{\prime}=d\left(\sigma_{z}^{\prime}-p^{\prime}\right)=d S_{z}$, Eq. (14) becomes

$$
\frac{d S_{z}}{S_{z}}=\frac{6 G^{\prime} d p^{\prime}}{K^{\prime} M^{2}\left(2 p^{\prime}-p_{c}{ }^{\prime}\right)}
$$

which can easily be integrated in order to determine $S_{z}$ and consequently, $\sigma_{z}{ }^{\prime}=S_{z}+p^{\prime}$. Two cases are considered

a) $G^{\prime}$ constant and $K^{\prime}$ stress dependent

Since $K^{\prime}=v p^{\prime} / k$, Eq. (15) reads

which, after integration, becomes

$$
\frac{d S_{z}}{S_{z}}=\frac{6 G^{\prime} k d p^{\prime}}{v M^{2} p^{\prime}\left(2 p^{\prime}-p_{c}{ }^{\prime}\right)}
$$

$$
S_{z}=S_{z i}\left[\frac{p_{i}{ }^{\prime}\left(2 p^{\prime}-p_{c}{ }^{\prime}\right)}{p^{\prime}\left(2 p_{i}{ }^{\prime}-p_{c}{ }^{\prime}\right)}\right]^{\frac{6 G^{\prime} k}{\nu M^{2} p_{c}{ }^{\prime}}}
$$


Analytical solution for undrained plane strain expansion of a cylindrical cavity in modified cam clay 25

where $S_{z i}=\sigma_{z i}{ }^{\prime}-p_{i}{ }^{\prime}, \sigma_{z i}{ }^{\prime}$ is the initial vertical effective stress, and $p_{i}{ }^{\prime}=\left(\sigma_{r i}{ }^{\prime}+\sigma_{\theta i}{ }^{\prime}+\sigma_{z i}{ }^{\prime}\right) / 3$ is the initial mean effective stress, with $\sigma_{r i}{ }^{\prime}=\sigma_{\theta i}{ }^{\prime}=K_{0} \sigma_{z i}{ }^{\prime}, \sigma_{r i}{ }^{\prime}$ and $\sigma_{\theta i}{ }^{\prime}$ being the initial radial and tangential effective stresses, respectively, as shown in Fig. 2. As a result, the vertical effective stress $\sigma_{z}^{\prime}=p^{\prime}+S_{z}$, or

$$
\sigma_{z}^{\prime}=p^{\prime}+\left(\sigma_{z i}{ }^{\prime}-p_{i}{ }^{\prime}\right)\left[\frac{p_{i}^{\prime}\left(2 p^{\prime}-p_{c}{ }^{\prime}\right)}{p^{\prime}\left(2 p_{i}{ }^{\prime}-p_{c}{ }^{\prime}\right)}\right]^{\frac{6 G^{\prime} k}{\nu M^{2} p_{c}{ }^{\prime}}}
$$

The effective radial and tangential stresses, $\sigma_{r}^{\prime}$ and $\sigma_{\theta}{ }^{\prime}$, are determined by substituting the expression for $\sigma_{z}{ }^{\prime}$ in Eqs. (1) and (2), and letting $\sigma_{1}{ }^{\prime}=\sigma_{r}{ }^{\prime}, \sigma_{2}{ }^{\prime}=\sigma_{z}{ }^{\prime}, \sigma_{3}{ }^{\prime}=\sigma_{\theta}{ }^{\prime}$. The stresses are

$$
\sigma_{r}{ }^{\prime}=p^{\prime}-\left(\frac{\sigma_{z i}{ }^{\prime}-p_{i}{ }^{\prime}}{2}\right)\left[\frac{p_{i}{ }^{\prime}\left(2 p^{\prime}-p_{c}{ }^{\prime}\right)}{p^{\prime}\left(2 p_{i}{ }^{\prime}-p_{c}{ }^{\prime}\right)}\right]^{\frac{6 G^{\prime} k}{\nu M^{2} p_{c}{ }^{\prime}}}+\frac{1}{2}\left\{\frac{4}{3} q^{2}-3\left(\sigma_{z i}{ }^{\prime}-p_{i}{ }^{\prime}\right)^{2}\left[\frac{p_{i}{ }^{\prime}\left(2 p^{\prime}-p_{c}{ }^{\prime}\right)}{p^{\prime}\left(2 p_{i}{ }^{\prime}-p_{c}{ }^{\prime}\right)}\right]^{\frac{12 G^{\prime} k}{\nu M^{2} p_{c}{ }^{\prime}}}\right\}^{1 / 2}
$$

and

$$
\sigma_{\theta}{ }^{\prime}=p^{\prime}-\left(\frac{\sigma_{z i}{ }^{\prime}-p_{i}{ }^{\prime}}{2}\right)\left[\frac{p_{i}{ }^{\prime}\left(2 p^{\prime}-p_{c}{ }^{\prime}\right)}{p^{\prime}\left(2 p_{i}{ }^{\prime}-p_{c}{ }^{\prime}\right)}\right]^{\frac{6 G^{\prime} k}{v M^{2} p_{c}{ }^{\prime}}}-\frac{1}{2}\left\{\frac{4}{3} q^{2}-3\left(\sigma_{z i}{ }^{\prime}-p_{i}{ }^{\prime}\right)^{2}\left[\frac{p_{i}{ }^{\prime}\left(2 p^{\prime}-p_{c}{ }^{\prime}\right)}{p^{\prime}\left(2 p_{i}{ }^{\prime}-p_{c}{ }^{\prime}\right)}\right]^{\frac{12 G^{\prime} k}{v M^{2} p_{c}{ }^{\prime}}}\right\}^{1 / 2}
$$

where the deviator stress $q$ is given by either Eq. (4a) or Eq. (4b).

The maximum shear stress, $\tau=\left(\sigma_{r}{ }^{\prime}-\sigma_{\theta}{ }^{\prime}\right) / 2$, is found from Eqs. (19). It is given by

$$
\tau=\frac{1}{2}\left\{\frac{4}{3} q^{2}-3\left(\sigma_{z i}{ }^{\prime}-p_{i}{ }^{\prime}\right)^{2}\left[\frac{p_{i}^{\prime}\left(2 p^{\prime}-p_{c}{ }^{\prime}\right)}{p^{\prime}\left(2 p_{i}{ }^{\prime}-p_{c}{ }^{\prime}\right)}\right]^{\frac{12 G^{\prime} k}{\nu M^{2} p_{c}}}\right\}^{1 / 2}
$$

b) $v^{\prime}$ or $G^{\prime} / K^{\prime}$ constant

Since $G^{\prime} / K^{\prime}=3\left(1-2 v^{\prime}\right) / 2\left(1+v^{\prime}\right)$, Eq. (15) becomes

$$
\frac{d S_{z}}{S_{z}}=\frac{9\left(1-2 v^{\prime}\right) d p^{\prime}}{M^{2}\left(1+v^{\prime}\right)\left(2 p^{\prime}-p_{c}^{\prime}\right)}
$$

which, after integration, leads to

$$
S_{z}=S_{z i}\left(\frac{2 p^{\prime}-p_{c}{ }^{\prime}}{2 p_{i}^{\prime}-p_{c}{ }^{\prime}}\right)^{\frac{9}{2 M^{2}}\left(\frac{1-2 v^{\prime}}{1+v^{\prime}}\right)}
$$

where, again, $S_{z i}=\sigma_{z i}{ }^{\prime}-p_{i}{ }^{\prime}$. As a consequence, the vertical effective stress $\sigma_{z}{ }^{\prime}$, which is equal to $p^{\prime}+S_{z}$, is given by

$$
\sigma_{z}^{\prime}=p^{\prime}+\left(\sigma_{z i}{ }^{\prime}-p_{i}{ }^{\prime}\right)\left(\frac{2 p^{\prime}-p_{c}{ }^{\prime}}{2 p_{i}{ }^{\prime}-p_{c}{ }^{\prime}}\right)^{\frac{9}{2 M^{2}}\left(\frac{1-2 v^{\prime}}{1+v^{\prime}}\right)}
$$


Substitution of this equation into Eqs. (1) and (2) permits the determination of the remaining principal stresses, $\sigma_{r}{ }^{\prime}, \sigma_{\theta}{ }^{\prime}$, as before. The stresses are

$$
\sigma_{r}^{\prime}=p^{\prime}-\left(\frac{\sigma_{z i}{ }^{\prime}-p_{i}{ }^{\prime}}{2}\right)\left(\frac{2 p^{\prime}-p_{c}{ }^{\prime}}{2 p_{i}{ }^{\prime}-p_{c}{ }^{\prime}}\right)^{\frac{9}{2 M^{2}}\left(\frac{1-2 v^{\prime}}{1+v^{\prime}}\right)}+\frac{1}{2}\left\{\frac{4}{3} q^{2}-3\left(\sigma_{z i}{ }^{\prime}-p_{i}\right)^{2}\left(\frac{2 p^{\prime}-p_{c}{ }^{\prime}}{2 p_{i}{ }^{\prime}-p_{c}{ }^{\prime}}\right)^{\frac{9}{2 M^{2}}\left(\frac{1-2 v^{\prime}}{1+v^{\prime}}\right)}\right\}^{1 / 2}
$$

and

$$
\sigma_{\theta}{ }^{\prime}=p^{\prime}-\left(\frac{\sigma_{z i}{ }^{\prime}-p_{i}{ }^{\prime}}{2}\right)\left(\frac{2 p^{\prime}-p_{c}{ }^{\prime}}{2 p_{i}{ }^{\prime}-p_{c}{ }^{\prime}}\right)^{\frac{9}{2 M^{2}}\left(\frac{1-2 v^{\prime}}{1+v^{\prime}}\right)}-\frac{1}{2}\left\{\frac{4}{3} q^{2}-3\left(\sigma_{z i}{ }^{\prime}-p_{i}{ }^{\prime}\right)^{2}\left(\frac{2 p^{\prime}-p_{c}{ }^{\prime}}{2 p_{i}{ }^{\prime}-p_{c}{ }^{\prime}}\right)^{\frac{9}{2 M^{2}}\left(\frac{1-2 v^{\prime}}{1+v^{\prime}}\right)}\right\}^{1 / 2}
$$

where, once again, the deviator stress $q$ is given by either Eq. (4a) or Eq. (4b).

The maximum shear stress, $\tau=\left(\sigma_{r}{ }^{\prime}-\sigma_{\theta}{ }^{\prime}\right) / 2$, is equal to

$$
\left.\left.\tau=\frac{1}{2}\left\{\frac{4}{3} q^{2}-3\left(\sigma_{z i}{ }^{\prime}-p_{i}{ }^{\prime}\right)^{2}\left(\frac{2 p^{\prime}-p_{c}{ }^{\prime}}{2 p_{i}{ }^{\prime}-p_{c}{ }^{\prime}}\right)^{\frac{9}{M^{2}}}\right\}^{1-2 v^{\prime}}\right)\right\}^{1 / 2}
$$

Remarks

Close examination of either Eq. (17) or Eq. (22) indicates that if the initial deviator stress $S_{z i}=0$, which corresponds to an initial isotropic stress state, with $\sigma_{r i}{ }^{\prime}=\sigma_{\theta i}{ }^{\prime}=\sigma_{z i}{ }^{\prime}=p_{i}{ }^{\prime}$, or $K_{0}=1$, then the current deviator stress $S_{z}$ is also zero and, consequently, $\sigma_{z}{ }^{\prime}=p^{\prime}$. Thus, $\sigma_{z}{ }^{\prime}=0.5\left(\sigma_{r}{ }^{\prime}+\sigma_{\theta}{ }^{\prime}\right)$ throughout the shearing process, because $\left(\sigma_{r}{ }^{\prime}+\sigma_{\theta}{ }^{\prime}\right)=3 p^{\prime}-\sigma_{z}{ }^{\prime}=3 \sigma_{z}{ }^{\prime}-\sigma_{z}{ }^{\prime}=2 \sigma_{z}{ }^{\prime}$. The principal stresses $\sigma_{r}{ }^{\prime}, \sigma_{\theta}{ }^{\prime}, \sigma_{z}{ }^{\prime}$ may be found either from Eqs. (23) and (24) by noting that $\left(\sigma_{z i}{ }^{\prime}-p_{i}{ }^{\prime}\right)=0$, or directly from the equation of the effective stress path (i.e., either Eq. (4a) or Eq. (4b)), for $p_{i}{ }^{\prime}=p_{0}{ }^{\prime}$. Indeed, since $\sigma_{z}{ }^{\prime}=0.5\left(\sigma_{r}{ }^{\prime}+\sigma_{\theta}{ }^{\prime}\right)$, the shear stress $\tau$ equals $q / \sqrt{3}$ from Eq. (2). Also, the mean effective stress $\sigma_{m}{ }^{\prime}=0.5\left(\sigma_{r}{ }^{\prime}+\sigma_{\theta}{ }^{\prime}\right)=p^{\prime}$ from Eq. (1). Thus, the principal effective stresses can be determined throughout the shearing process from the following expressions

$$
\begin{aligned}
& \sigma_{r}{ }^{\prime}=p^{\prime}+q / \sqrt{3} \\
& \sigma_{\theta}{ }^{\prime}=p^{\prime}-q / \sqrt{3} \\
& \sigma_{z}{ }^{\prime}=p^{\prime}
\end{aligned}
$$

In addition, the principal effective stresses at critical state are given by

$$
\begin{aligned}
\sigma_{r f}^{\prime} & =[(\sqrt{3} / M)+1] S_{u} \\
\sigma_{\theta f^{\prime}} & =[(\sqrt{3} / M)-1] S_{u} \\
\sigma_{z f^{\prime}} & =(\sqrt{3} / M) S_{u}
\end{aligned}
$$

where the undrained shear strength $S u=\left(\sigma_{r f}{ }^{\prime}-\sigma_{\theta f}{ }^{\prime}\right) / 2=q_{f} f \sqrt{3}$ and $q_{f}=p_{f}{ }^{\prime} M=2^{-\Lambda} p_{0}{ }^{\prime} M$. It should 
be stressed that Eqs. (26) and 27 are valid only for the case of $K_{0}=1$.

\subsection{Maximum shearing strains}

The maximum shearing strain $\gamma=\left|\varepsilon_{r}-\varepsilon_{\theta}\right|=2 \varepsilon_{\theta}$, because $\varepsilon_{z}=0$ and $\varepsilon_{r}=-\varepsilon_{\theta}$ in plane strain and undrained conditions.

Initial anisotropic stress state $\left(K_{0} \neq 1\right)$

The shearing strain $\gamma$ is determined by summation or integration of the strain increment $d \varepsilon_{r}$ $\left(=-d \varepsilon_{\theta}\right)$ in Eq. (10a) or Eq. (10b). The result is

a) For $G^{\prime}$ constant and $K^{\prime}$ stress dependent,

$$
\gamma=\frac{\tau}{G^{\prime}}-\frac{6 k}{v M^{2}} \int_{p_{i}^{\prime}}^{p^{\prime}} \frac{\tau d p^{\prime}}{p^{\prime}\left(2 p^{\prime}-p_{c}{ }^{\prime}\right)}
$$

where the shear stress $\tau$ is given by Eq. (20). Note also that $d p^{\prime}$ is negative in Eq. (28a), since $p^{\prime}$ decreases during shearing. The derivation of Eq. (28a) is shown in the appendix.

b) For $v^{\prime}$ or $G^{\prime} / K^{\prime}$ constant,

$$
\gamma=\frac{2\left(1+v^{\prime}\right)}{3\left(1-2 v^{\prime}\right)} \frac{k}{v} \int_{0}^{\tau} \frac{d \tau}{p^{\prime}}-\frac{6 k}{v M^{2}} \int_{p_{i}^{\prime}}^{p^{\prime}} \frac{\tau d p^{\prime}}{p^{\prime}\left(2 p^{\prime}-p_{c}{ }^{\prime}\right)}
$$

where the shear stress $\tau$ is given by Eq. (25). Again, the increment $d p^{\prime}$ is negative in Eq. (28b). The derivation of Eq. (28b) is also shown in the appendix.

Initial isotropic stress state $\left(K_{0}=1\right)$

As mentioned previously, the vertical effective stress $\sigma_{z}{ }^{\prime}$ is always equal to $0.5\left(\sigma_{r}{ }^{\prime}+\sigma_{\theta}{ }^{\prime}\right)$ or to $p^{\prime}$ in this case (See Eq. (26c)). The shear stress from Eqs. (26a) and (26b). The shearing strain $\gamma=\left|\varepsilon_{r}-\varepsilon_{\theta}\right|=\sqrt{3} \varepsilon_{q}$, since $\varepsilon_{z}=0$ and $\varepsilon_{r}=-\varepsilon_{\theta}$. Thus, Eqs. (5) and (6) allow to obtain in closed form the corresponding shear stress-shear strain relationships. These are

a) For $G^{\prime}$ constant and $K^{\prime}$ stress dependent,

$$
\gamma=\frac{\tau}{G^{\prime}}+\frac{2 \sqrt{3} k \Lambda}{v M}\left[\tanh ^{-1}\left(\frac{\sqrt{3} \tau}{\sigma_{m}{ }^{\prime} M}\right)-\tan ^{-1}\left(\frac{\sqrt{3} \tau}{\sigma_{m}{ }^{\prime} M}\right)\right]
$$

and

b) For $v^{\prime}$ or $G^{\prime} / K^{\prime}$ constant,

$$
\gamma=\frac{2 \sqrt{3}}{9} \frac{\left(1+v^{\prime}\right)}{\left(1-2 v^{\prime}\right)} \frac{k}{v}\left[\frac{\sqrt{3} \tau}{\sigma_{m}{ }^{\prime}}(1-2 \Lambda)+2 \Lambda M \tan ^{-1}\left(\frac{\sqrt{3} \tau}{\sigma_{m}{ }^{\prime} M}\right)\right]+\frac{2 \sqrt{3} k \Lambda}{v M}\left[\tanh ^{-1}\left(\frac{\sqrt{3} \tau}{\sigma_{m}{ }^{\prime} M}\right)-\tan ^{-1}\left(\frac{\sqrt{3} \tau}{\sigma_{m}{ }^{\prime} M}\right)\right]
$$

where the shear stress $\tau=q / \sqrt{3}$ and the mean effective stress $\sigma_{m}{ }^{\prime}=\left(\sigma_{r}{ }^{\prime}+\sigma_{\theta}{ }^{\prime}\right) / 2=\sigma_{z}{ }^{\prime}=p^{\prime}$.

\subsection{Total radial stress and excess pore pressures}

As strains of finite magnitude are considered in the analysis, it will be in order to distinguish the distance $r$ of a point in the unstrained condition in the medium surrounding the cylindrical cavity and the corresponding distance $r^{\prime}$ of the same material element in the strained condition, similarly the cavity radius $a$ before, and $a^{\prime}$ after the distortion has occurred.

The finite (natural, logarithmic, or true) tangential strain $\varepsilon_{\theta}$ is given by 


$$
\varepsilon_{\theta}=\ln \left(\frac{r^{\prime}}{r}\right)=\frac{1}{2} \ln \left(\frac{r^{\prime}}{r}\right)^{2}
$$

Consequentely, the maximum shearing strain $\gamma$, which equals $2 \varepsilon_{\theta}$, becomes

$$
\gamma=\ln \left(\frac{r^{\prime}}{r}\right)^{2}
$$

Since the expansion takes place in undrained and plane strain conditions, the following relation

$$
a^{\prime 2}-a^{2}=r^{\prime 2}-r^{2}
$$

holds among the radii. The equation of equilibrium

$$
\gamma^{\prime} \frac{d \sigma_{r}}{d r^{\prime}}=-\left(\sigma_{r}-\sigma_{\theta}\right)=-2 \tau
$$

leads to (See, for example, Nadai 1950 and Yu 2000)

$$
d \sigma_{r}=\frac{\tau d \gamma}{e^{\gamma}-1}
$$

because $2 d r^{\prime} / r^{\prime}=-d \gamma\left(e^{\gamma}-1\right)$ from Eqs. (31) and (32). The total radial stress $\sigma_{r}$ is determined by integration of Eq. (34), resulting in

$$
\sigma_{r}=\int_{0}^{\gamma} \frac{\tau d \gamma}{e^{\gamma}-1}+\sigma_{r i}
$$

At the cavity interface, the radial stress $\sigma_{r a}$ is given by

$$
\sigma_{r a}=\int_{0}^{\gamma} \frac{\tau d \gamma}{e^{\gamma}-1}+\sigma_{r i}
$$

where $\sigma_{r i}=\sigma_{r i}{ }^{\prime}+u_{0}$, with $u_{0}=$ initial pore water pressure, and $\gamma_{a}=\ln \left(a^{\prime} / a\right)^{2}$ is the cavity shear strain. Eq. (35) must be evaluated numerically because the function $\tau /\left(e^{\gamma}-1\right)$ is complex. The total tangential stress $\sigma_{\theta}$ is obtained by subtracting $2 \tau$ from the total radial stress $\sigma_{r}$.

Although the finite (natural) strain theory is particularly attractive because of its physical interpretation, prediction of the limit expansion pressure is not possible, for the upper limit of the integral in Eq. (35b) must be extended to infinity. In such case, another strain definition has to be used in order to form strain tensors and express the rheological properties of the material (Baguelin et al. 1978). In particular, the Almansi (or Euler) strains can be employed. The Almansi tangential strain $\alpha$ which is defined as

$$
\alpha=\frac{1}{2}\left(\frac{{r^{\prime}}^{2}-r^{2}}{r^{\prime 2}}\right)
$$

becomes

$$
\alpha_{0}=\frac{1}{2}\left(\frac{a^{\prime 2}-a^{2}}{a^{\prime 2}}\right)
$$

at the wall of the cavity. 
Combining Eqs. (32) and (37) shows that the shear strain $\gamma=\ln [1 /(1-2 \alpha)]$. Consequently, Eqs. (35) become

$$
\sigma_{r}=\int_{0}^{\alpha} \frac{\tau d \alpha}{\alpha}+\sigma_{r i}
$$

and

$$
\sigma_{r a}=\int_{0}^{\alpha_{0}} \frac{\tau d \alpha}{\alpha}+\sigma_{r i}
$$

because $d \gamma /\left(e^{\gamma}-1\right)=d \alpha / \alpha$. The limit expansion pressure $\sigma_{r f}$ is found from Eq. (38b), by simply extending the upper limit $\alpha_{0}$ of the integral to 0.5. Indeed, Eq. (37) indicates that $\alpha_{0}=0.5$ for $a^{\prime} / a=\infty$. In such case the shearing strain $\gamma_{a}$ mobilized at the cavity interface is also equal to infinity.

The limit pore pressure $u_{f}$ may be found by substracting the radial effective stress at critical state $\sigma_{r f}^{\prime}$ from the limit expansion pressure $\sigma_{r f}$.

Remarks

a) Initial isotropic stress state $\left(K_{0}=1\right)$

As discussed previously, the principal effective stresses $\sigma_{r}{ }^{\prime}, \sigma_{\theta}{ }^{\prime}, \sigma_{z}{ }^{\prime}$ can be found directly from the equation of the effective stress path in $q-p^{\prime}$ plane, because $\sigma_{z}{ }^{\prime}=0.5\left(\sigma_{r}{ }^{\prime}+\sigma_{\theta}{ }^{\prime}\right)=p^{\prime}$. The shear stress $\tau=\left(\sigma_{r}{ }^{\prime}-\sigma_{\theta}{ }^{\prime}\right) / 2=q / \sqrt{3}$. As for the shearing strain $\gamma$, it is given directly by Eqs. (29). Consequently, the radial stresses $\sigma_{r}$ and $\sigma_{r a}$ are obtained by substitution of the values of $\tau$ and $\gamma$ in Eqs. (35). It should be again noted that evaluation of the radial stresses must be carried out numerically.

b) Finite strain approach

As mentioned above, the Almansi finite strain approach was used to obtain the limit expansion pressure by simply extending the upper limit $\alpha_{0}$ of the integral in Eq. (38b) to $\alpha_{0}=0.5$. The finite (natural, logarithmic, or true) strain approach expressed by Eq. (35b) could also have been used, except that the upper limit $\gamma_{a}$ of the integral would have had to be extended to $\gamma_{a}=\infty$. This could have resulted in difficulties for the numerical evaluation of the integral in Eq. (35b). However, because Eqs. (35b) and (38b) are equivalent they yield the same result, except that Eq. (38b) is more easily amenable to numerical integration.

The shear strain $\gamma$ used in the present study is based upon the finite (natural, logarithmic, or true) strain approach, as expressed by Eq. (31). Because this approach is related to that of the Almansi strain (i.e., Eq. (36)), it was quite simple to derive Eqs. (38) from Eqs. (35).

Concerning the Almansi strain approach used to obtain the limit expansion pressure, it was also employed by Baguelin et al. (1978) for the analysis of the pressuremeter test in clay, and by De Souza Coutinho (1990) for the analysis of the expansion of cylindrical cavities in sand.

$\mathrm{Yu}$ (2000) used the natural strain approach for the numerical analysis of the expansion of a cylindrical cavity in London clay, which was modelled as modified Cam clay. However, in his analysis, the vertical effective stress $\sigma_{z}^{\prime}$ was obtained from the other two stress components $\sigma_{r}{ }^{\prime}$ and $\sigma_{\theta}{ }^{\prime}$, by using the plane strain condition in the vertical direction. This condition requires both the elastic and plastic vertical strain increments to be zero.

As for Gibson and Anderson (1961), they used the small (engineering) strain approach for the elastic phase of the deformation, and the Almansi strain approach for the plastic phase of deformation. Finally, Palmer (1972) used the Almansi strain approach throughout the expansion process. 


\section{Application and comparison}

The method developed in the previous sections was applied to the problem analysed by Carter et al. (1979) and Randolph et al. (1979). The results are compared firstly with those reported by these authors which were obtained by means of the finite element method, and secondly with those reported by Itasca (1995) which were determined using the finite difference method.

Carter et al. (1979) and Randolph et al. (1979) considered the plane strain expansion of a cylindrical cavity in remoulded Boston Blue clay, which was modelled as modified Cam clay. The soil properties were: $v=2.16, K_{0}=0.55, \sigma_{r i}{ }^{\prime}=\sigma_{\theta i}{ }^{\prime}=1.65 S_{u}, \sigma_{z}{ }^{\prime}=3 S_{u}$, initial pore water pressure $u_{0}=0, M=1.2\left(\right.$ or $\left.\phi^{\prime}=30^{\circ}\right), \lambda=0.15, \kappa=0.03, \Lambda=(\lambda-\kappa) / \lambda=0.8$ and $G^{\prime}=74 S_{u}$ with $S_{u}=$ undrained shear strength.

For illustration purposes, the in situ effective normal stresses in the present study were given the values, $\sigma_{z i}{ }^{\prime}=300 \mathrm{kPa}, \sigma_{r i}{ }^{\prime}=\sigma_{\theta i}{ }^{\prime}=165 \mathrm{kPa}$, yielding $p_{i}{ }^{\prime}=\left(1+2 K_{0}\right) \sigma_{z i}{ }^{\prime} / 3=210 \mathrm{kPa}, S_{z i}=\sigma_{z i}{ }^{\prime}-p_{i}{ }^{\prime}$ $=90 \mathrm{kPa}, q_{i}=\left(1-K_{0}\right) \sigma_{z i}{ }^{\prime}=135 \mathrm{kPa}$ and $\eta_{i}=q_{i} / p_{i}{ }^{\prime}=0.643$.

The effective stress path in $q-p^{\prime}$ plane is shown in Fig. 3. The hardening parameter $p_{c}{ }^{\prime}$ is found to be $270 \mathrm{kPa}$ The parameter $p_{0}{ }^{\prime}$ equals $257 \mathrm{kPa}$. The effective stress path begins at $p_{i}{ }^{\prime}=210 \mathrm{kPa}$, $q_{i}=135 \mathrm{kPa}$ and ends at $p_{f}^{\prime}=2^{-\Lambda} p_{0}{ }^{\prime}=147.6 \mathrm{kPa}, q_{f}=M p_{f}^{\prime}=177.1 \mathrm{kPa}$. The undrained shear strength $S_{u}$ would be equal to $q_{f} / \sqrt{3}$ or $102.3 \mathrm{kPa}$, if and only if one retained the assumption that $\sigma_{z f}{ }^{\prime}=0.5\left(\sigma_{r f}{ }^{\prime}+\sigma_{\theta f^{\prime}}\right)$, with $\sigma_{r f}{ }^{\prime}, \sigma_{z f^{\prime}}, \sigma_{\theta f^{\prime}}$ being the principal effective stresses at critical state.

For direct comparison with the results obtained by Carter et al. (1979) and Randolph et al. (1979), the shear modulus $G^{\prime}$ was taken equal to $74 S_{u}$ or $74 \times 102.3=7570 \mathrm{kPa}$. Eqs. (18) and (19) were used to obtain the principal effective stresses $\sigma_{z}{ }^{\prime}, \sigma_{r}{ }^{\prime}, \sigma_{\theta}{ }^{\prime}$. For example, let it be required to

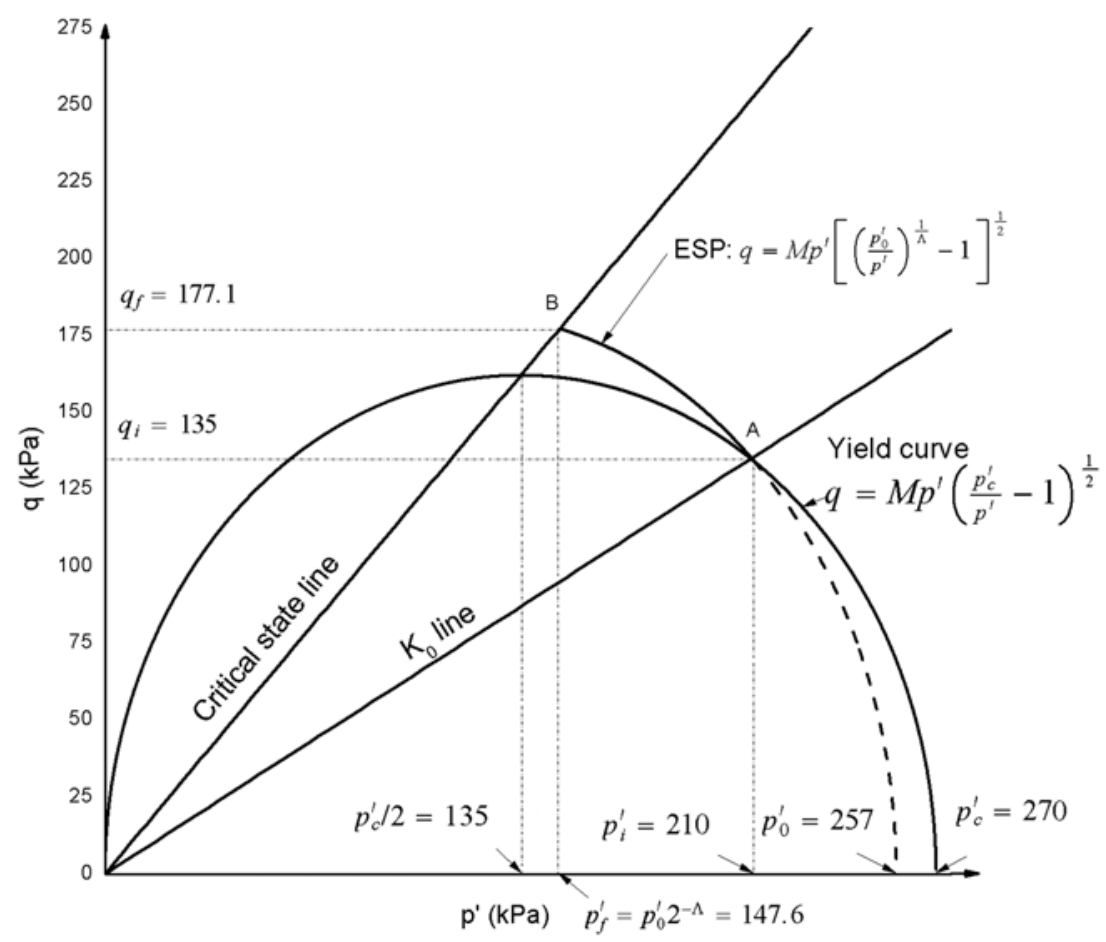

Fig. 3 Yield curve and effective stress path 


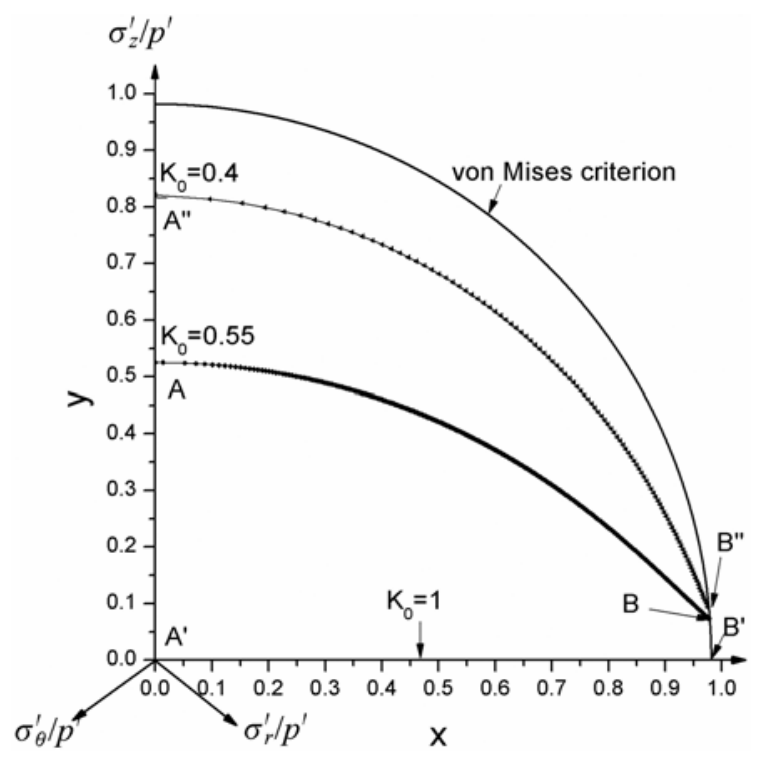

Fig. 4 Effective stress paths on $\pi$-plane

determine these stresses when $p^{\prime}=180 \mathrm{kPa}$ and $q=161.7 \mathrm{kPa}$. Application of Eq. (18) gives $\sigma_{z}{ }^{\prime}=$ $230.5 \mathrm{kPa}$ for $S_{z i}=\sigma_{z i}{ }^{\prime}-p_{i}{ }^{\prime}=90 \mathrm{kPa}, M=1.2, v=2.16, k=0.03, p_{c}{ }^{\prime}=270 \mathrm{kPa}$, and $p_{i}{ }^{\prime}=210 \mathrm{kPa}$. Eqs. (19) result in $\sigma_{r}{ }^{\prime}=237.3 \mathrm{kPa}$ and $\sigma_{\theta}{ }^{\prime}=72.3 \mathrm{kPa}$. In addition, the shear stress $\tau=\left(\sigma_{r}{ }^{\prime}-\sigma_{\theta}{ }^{\prime}\right) / 2$ $=82.5 \mathrm{kPa}$ from Eq. (20). Also, the principal stresses at critical state are $\sigma_{r f}{ }^{\prime}=245.2 \mathrm{kPa}$, $\sigma_{z f}{ }^{\prime}=156.5 \mathrm{kPa}$, and $\sigma_{\theta f^{\prime}}=41.2 \mathrm{kPa}$, leading to $\tau_{f}=\left(\sigma_{r f}^{\prime}-\sigma_{\theta f^{\prime}}\right) / 2=102.0 \mathrm{kPa}$, as also postulated by Carter et al. (1979) on the basis of $S_{u}=q_{f} / \sqrt{3}$. The vertical effective stress $\sigma_{z f}{ }^{\prime}$ is found to be equal to $0.55\left(\sigma_{r f}{ }^{\prime}+\sigma_{\theta f}{ }^{\prime}\right)$, which is different from the commonly assumed value of $0.5\left(\sigma_{r f}{ }^{\prime}+\sigma_{\theta f}{ }^{\prime}\right)$, encountered in ideal plasticity. Furthermore, the factor which multiplies the sum $\left(\sigma_{r f}{ }^{\prime}+\sigma_{\theta f}{ }^{\prime}\right)$ depends on the in situ stress state: the lower the value of $K_{0}$, the higher the value of this factor, as shown next.

By normalizing the principal effective stresses with respect to the corresponding value of $p^{\prime}$, it becomes possible to draw the effective stress path on the $\pi$-plane, that is, the plane which is perpendicular to the space diagonal $\left(\sigma_{r}{ }^{\prime}=\sigma_{\theta}{ }^{\prime}=\sigma_{z}{ }^{\prime}\right)$, as shown in Fig. 4. The coordinates $x, y$ used to draw the path are given by (See, for example, Mendelson 1968)

$$
\begin{gathered}
x=\frac{\sigma_{r}{ }^{\prime}-\sigma_{\theta}{ }^{\prime}}{\sqrt{2} p^{\prime}} \\
y=\frac{2 \sigma_{z}{ }^{\prime}-\sigma_{\theta}{ }^{\prime}-\sigma_{r}{ }^{\prime}}{\sqrt{6} p^{\prime}}
\end{gathered}
$$

The effective stress path begins at point A $(x=0, y=0.525)$, corresponding to $\sigma_{r}{ }^{\prime}=\sigma_{\theta}{ }^{\prime}=165 \mathrm{kPa}$, $\sigma_{z i}{ }^{\prime}=300 \mathrm{kPa}$, and $p_{i}{ }^{\prime}=210 \mathrm{kPa}$. It ends at point $\mathrm{B}(x=0.977, y=0.074)$ for $\sigma_{r f}{ }^{\prime}=245.2 \mathrm{kPa}$, $\sigma_{z f}{ }^{\prime}=156.5 \mathrm{kPa}, \sigma_{\theta}^{\prime}=41.2 \mathrm{kPa}$, and $p^{\prime}=p_{f}^{\prime}=147.6 \mathrm{kPa}$. Also $\tau_{f}=\sigma_{r f}{ }^{\prime}-\sigma_{\theta f^{\prime}} / 2=102.0 \mathrm{kPa}$.

An effective stress path which begins at an isotropic stress state represented by $\sigma_{r i}{ }^{\prime}=\sigma_{\theta i}{ }^{\prime}=\sigma_{z i}{ }^{\prime}=p_{i}{ }^{\prime}=p_{0}{ }^{\prime}$ $=257 \mathrm{kPa}$ (i.e., for $K_{0}=1$ ), is also shown in Fig. 4. The path begins at point $A^{\prime}(x=0, y=0)$ and ends at point $B^{\prime}(x=0.98, y=0)$ corresponding to $\sigma_{r f}^{\prime}=249.9 \mathrm{kPa}, \sigma_{z f}^{\prime}=p_{f}^{\prime}=147.6 \mathrm{kPa}$, and $\sigma_{\theta f}{ }^{\prime}=$ 
$45.3 \mathrm{kPa}$, implying that $\sigma_{z f}{ }^{\prime}=0.5\left(\sigma_{r f}{ }^{\prime}+\sigma_{\theta f}{ }^{\prime}\right)$ and $\tau_{f}=q_{f} / \sqrt{3}=102.3 \mathrm{kPa}$. In addition, the vertical effective stress $\sigma_{z}{ }^{\prime}$ is equal to $0.5\left(\sigma_{r}{ }^{\prime}+\sigma_{\theta}{ }^{\prime}\right)$ throughout the shearing process in this case.

An additional effective stress path corresponding to $K_{0}=0.4$ or $\eta_{i}=3\left(1-K_{0}\right) /\left(1+2 K_{0}\right)=1$ has been included in Fig. 4 for comparison purposes. The initial stress state is represented by $p_{i}{ }^{\prime}=q_{i}=168.5 \mathrm{kPa}$ for $\sigma_{z i}{ }^{\prime}=280.9 \mathrm{kPa}, \sigma_{r i}{ }^{\prime}=\sigma_{\theta i}{ }^{\prime}=0.4 \sigma_{z i}{ }^{\prime}=112.4 \mathrm{kPa}$, and $S_{z i}=\sigma_{z i}{ }^{\prime}-p_{i}{ }^{\prime}=112.4$ $\mathrm{kPa}$. The principal effective stresses $\sigma_{r}{ }^{\prime}, \sigma_{\theta}{ }^{\prime}, \sigma_{z}{ }^{\prime}$ were again determined from Eqs. (18) and (19). The stress path begins at point $\mathrm{A}^{\prime \prime}(x=0, y=0.816)$ and ends at point $\mathrm{B}^{\prime \prime}(x=0.980, y=0.117)$ corresponding to $\sigma_{r f}^{\prime}=239.3 \mathrm{kPa}, \sigma_{z f}^{\prime}=158.1 \mathrm{kPa}, \sigma_{\theta f^{\prime}}=34.8 \mathrm{kPa}$, and $p_{f}^{\prime}=147.6 \mathrm{kPa}$. As a result, $\tau_{f}=\sigma_{r f}{ }^{\prime}-\sigma_{\theta f^{\prime}} / 2=102.3 \mathrm{kPa}$. Again, this is equal to $q_{f} / \sqrt{3}=102.3 \mathrm{kPa}$. In addition, $\sigma_{z f}{ }^{\prime}=$ $0.58\left(\sigma_{r}^{\prime}+\sigma_{\theta}^{\prime}\right)$.

Examination of the end points of the effective stress paths shown in Fig. 4 indicates that they are all located on the same circle (i.e., a von Mises criterion), as they should be since $q_{f}$ is constant $(=177.1 \mathrm{kPa})$ for these paths.

The maximum shear stress versus the finite (natural, logarithmic, or true) shear straincurve, obtained for $K_{0}=0.55$ is shown in Fig. 5. While the maximum shear stress, $\tau=\left(\sigma_{r}{ }^{\prime}-\sigma_{\theta}{ }^{\prime}\right) / 2$, was calculated by means of Eq. (20), the shearing strain $\gamma$ was found from Eq. (28a). The initial slope $G^{\prime}$ of the curve is equal to $7570 \mathrm{kPa}$. The ultimate value of $\tau$, that is, $\tau_{f}=102.0 \mathrm{kPa}$. The deviator stress at failure $q_{f}$ which corresponds to $\tau_{f}=102.0 \mathrm{kPa}$ is equal to $177.1 \mathrm{kPa}$, as shown in Fig. 3 . Such value of $q_{f}$ compares well with $q_{f}=176$. $\mathrm{kPa}$ deduced from Carter et al. (1979) and $q_{f}=177.8$ $\mathrm{kPa}$ found from the numerical results given by Itasca (1995).

In Fig. 5 is also shown for comparison purposes the stress-strain curve obtained from the elastic perfectly plastic approach of Gibson and Anderson (1961), for $G=7570 \mathrm{kPa}$ and $\tau_{f}=102.0 \mathrm{kPa}$. It appears that the latter relationship is relatively close to that obtained using modified Cam clay for the case studied.

The total radial stress $\sigma_{r a}$ acting at the cavity interface was determined by means of Eq. (38b). It is presented in normalized form, $\sigma_{r a} / \tau_{f}$, in Figs. 6 and 7 as function of the cavity ratio $a^{\prime} / a$. This

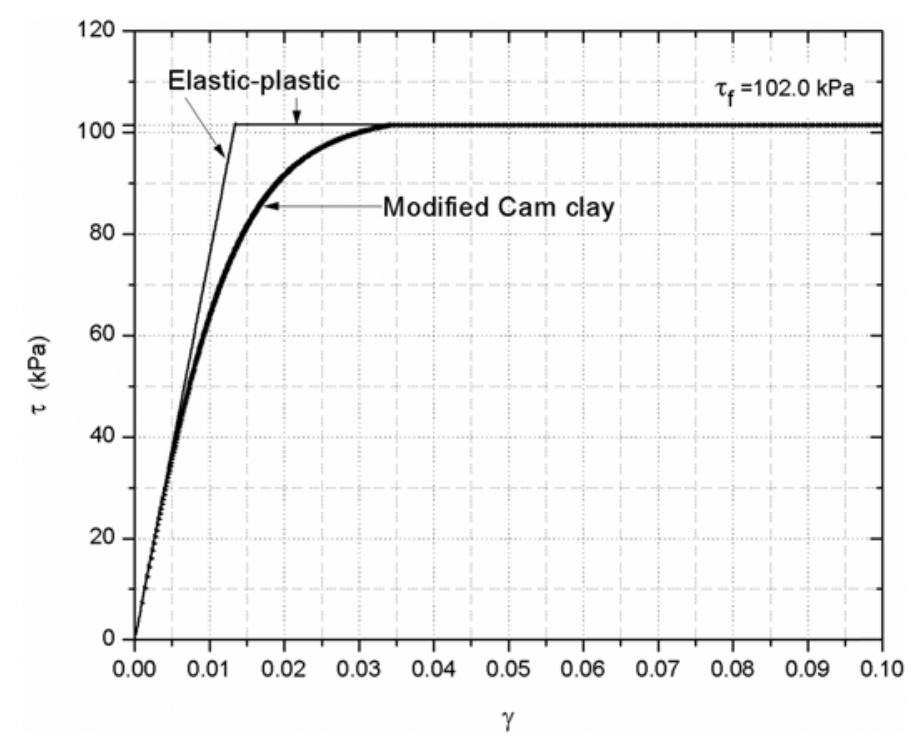

Fig. 5 Stress-strain curves for $K_{0}=0.55$ 
Analytical solution for undrained plane strain expansion of a cylindrical cavity in modified cam clay 33

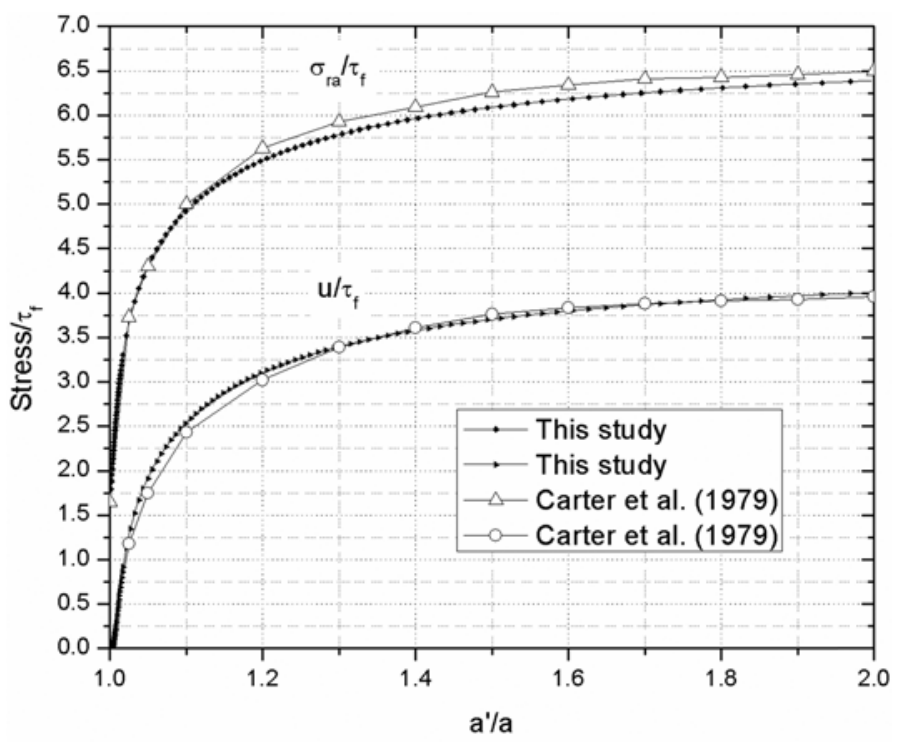

Fig. 6 Comparison of normalized pore pressure and total radial stress at the cavity interface with results obtained by Carter et al. (1979)

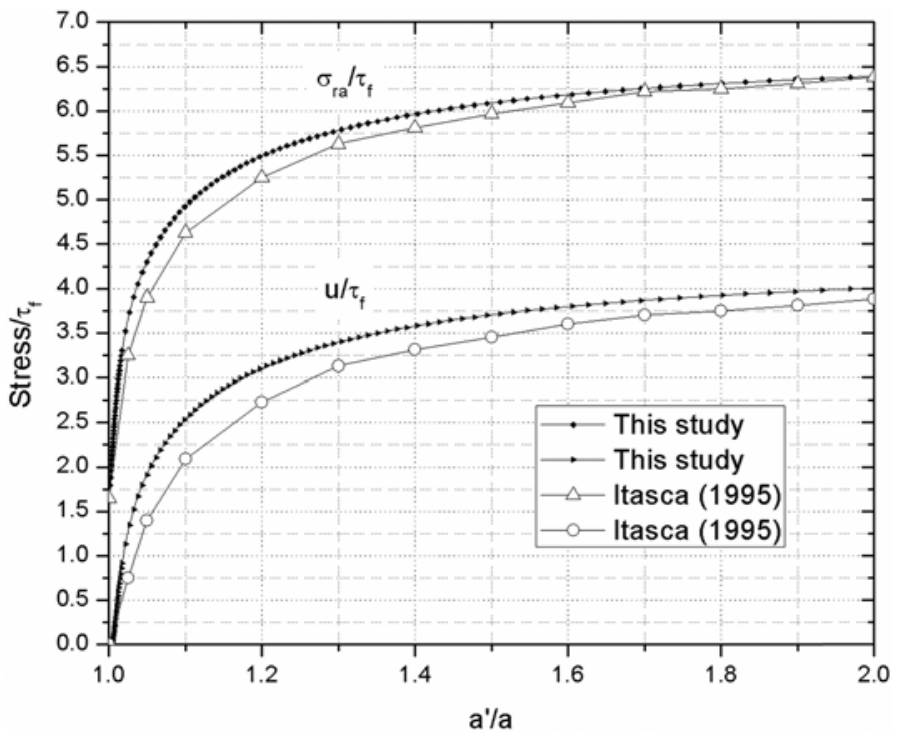

Fig. 7 Comparison of normalized pore pressure and total radial stress at the cavity interface with results reported by Itasca (1995)

ratio, which is equal to $e^{\gamma_{a} / 2}$ from Eq. (31), and to $\left[1 /\left(1-2 \alpha_{0}\right)\right]^{1 / 2}$ from Eq. (37), reaches a value of 2 for $\gamma_{a}=1.386$ or $\alpha_{0}=0.375$. The normalized pore water pressure, $u / \tau_{f}$, is also reported in Figs. 6 and 7. The results are also compared with the curves obtained by Carter et al. (1979) and Itasca (1995) in Figs. 5 and 6, respectively. Examination of the relationships shown indicates that there is good agreement between the results obtained in this study and the numerical analyses reported by the latter investigators. 


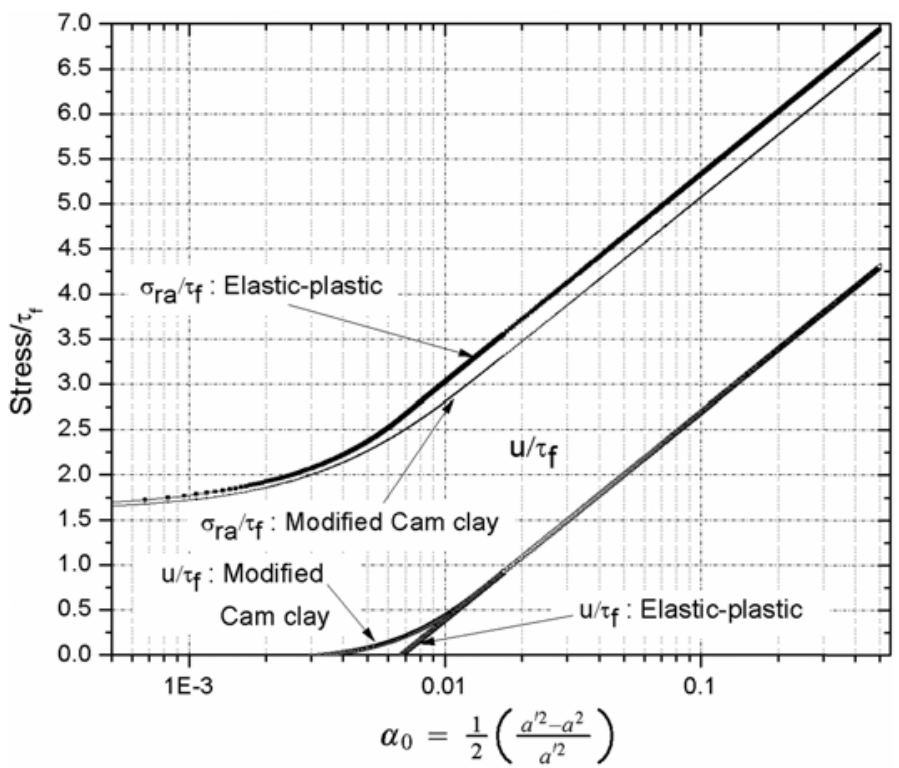

Fig. 8 Pore pressure and total radial stress response at the cavity interface as function of the Almansi tangential strain $\alpha_{0}$

Fig. 8 presents the radial stress $\sigma_{r a}$ and the excess pore water pressure $u$ generated at the cavity interface as a function of the logarithm of the Almansi tangential strain $\alpha_{0}$. The limit values of the radial stress $\sigma_{r a}$ and the pore pressure $u$ acting at the cavity interface were determined by extending the upper limit $\alpha_{0}$ of the integral in Eq. (38b) to $\alpha_{0}=0.5$, yielding $\sigma_{r f}=684 \mathrm{kPa}$ or $6.74 \tau_{f}$ and

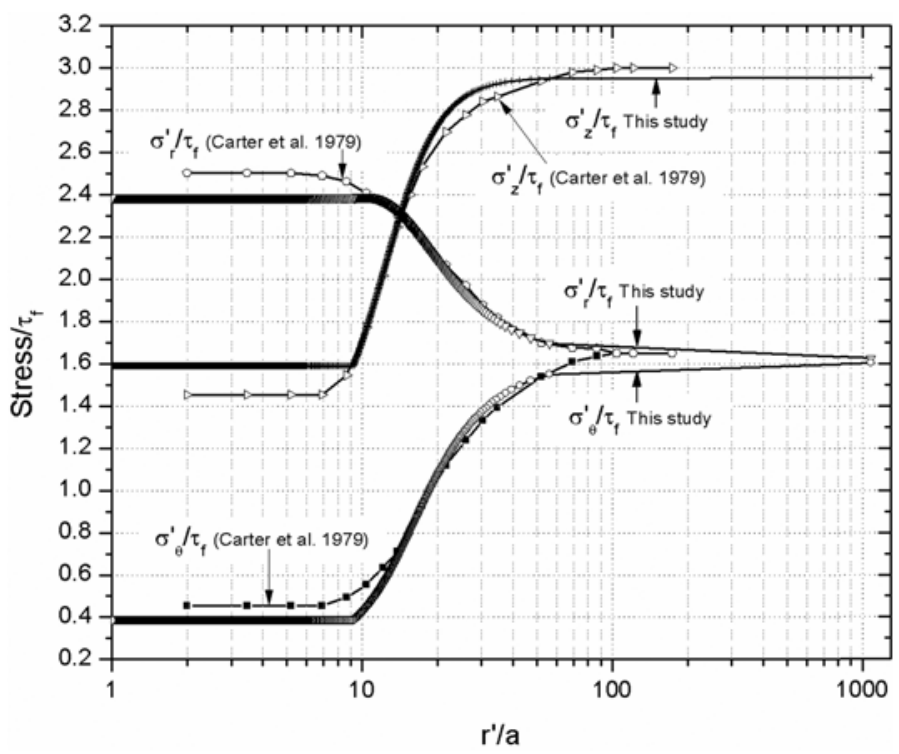

Fig. 9 Stress distributions after cavity expansion for $a^{\prime} / a=2$ and comparison with results obtained by Carter et al. (1979) 


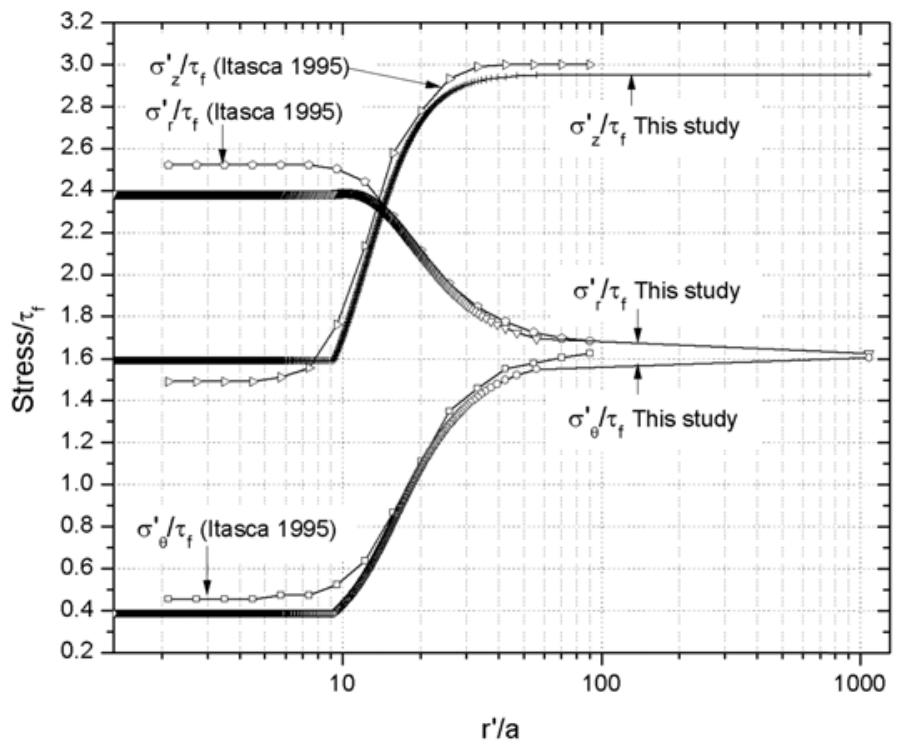

Fig. 10 Stress distributions after cavity expansion for $a^{\prime} / a=2$ and comparison with results reported by Itasca (1995)

$u_{f}=429 \mathrm{kPa}$ or $4.33 \tau_{f}$, with $\tau_{f}=102.0 \mathrm{kPa}$. Such values compare well with $\sigma_{r f} \approx 6.6 \tau_{f}$ and $u_{f} \approx 4.2 \tau_{f}$ (Carter et al. 1979), and $\sigma_{r f} \approx 7.0 \tau_{f}$ and $u_{f} \approx 4.5 \tau_{f}$ (Itasca 1995), respectively.

In Fig. 8 are also shown for comparison purposes, the corresponding relationships obtained using the elastic perfectly plastic approach of Gibson and Anderson (1961), for $G=7570 \mathrm{kPa}$ and $\tau_{f}=102$ $\mathrm{kPa}$. Examination of the curves reported in Fig. 8 indicates that in the plastic region the excess pore pressure given by the elastic perfectly plastic relationship is practically equal to that obtained from modified Cam clay. In addition, the limit radial pressure $\sigma_{r f}$ and the excess pore pressure $u_{f}$ which are given by $\sigma_{r f}=\sigma_{r i}+S_{u} \ln \left[1+\ln \left(G / \tau_{f}\right)\right]$ and $u_{f}=S_{u} \ln \left(G / \tau_{f}\right)$ for the elastic perfectly plastic model are equal, respectively, to $\sigma_{r f}=706.3 \mathrm{kPa}$ or $6.92 \tau_{f}$ and $u_{f}=439.3 \mathrm{kPa}$ or $4.31 \tau_{f}$.

It is also interesting to observe that the slopes of the relationships deduced from modified Cam clay shown in Fig. 8, that is, $d \sigma_{r a} d \ln \alpha_{0}$ and $d u / d \ln \alpha_{0}$, are approximately equal to one for strains $\alpha_{0} \geq 0.025$ corresponding to $a^{\prime} / a \geq 1.026$ or $\gamma_{a} \geq 0.051$.

Figs. 9 and 10 present the distributions of the effective stresses around the cylindrical cavity when the cavity ratio $a^{\prime} / a=2$. The results are compared first with those obtained by Carter et al. (1979) in Fig. 9, and second with those reported by Itasca (1995) in Fig. 10. The curves reported by Carter et al. (1979) had to be shifted horizontally because the initial radius of the cavity was chosen to be $r /$ $\sqrt{3}$. Examination of the curves shown in these two figures indicates once again that the results obtained in this study compare well with those reported by the latter authors. The good agreement is due in large part to the fact that the end point of the stress path for $K_{0}=0.55$ is relatively close to that found for $K_{0}=1$, as shown in Fig. 4 .

\section{Conclusions}

The following main conclusions are drawn on the basis of the contents of this paper. 
The principal stresses $\sigma_{r}{ }^{\prime}, \sigma_{\theta}{ }^{\prime}, \sigma_{z}{ }^{\prime}$ generated around an expanding cylindrical cavity are determined from the modified Cam Clay stress-strain relationships. It is shown that the vertical effective stress $\sigma_{z}{ }^{\prime}$ is not equal, in general, to the mean of the other two principal stresses, $\sigma_{r}^{\prime}$ and $\sigma_{\theta}{ }^{\prime}$, at critical state. However, $\sigma_{z}{ }^{\prime}$ is always equal to $0.5\left(\sigma_{r}{ }^{\prime}+\sigma_{\theta}{ }^{\prime}\right)$ when shearing commences from an isotropic stress state.

The stress-strain relationships are applied to the expansion of a cylindrical cavity in remoulded Boston Blue clay. The results compare well with those obtained from finite element and finite difference studies by Carter et al. (1979) and Itasca (1995), respectively.

\section{Acknowledgments}

The authors wish to acknowledge the financial support provided by the Natural Sciences and Engineering Research Council of Canada (NSERC). The authors also express their gratitude to the reviewers for their constructive comments, which allowed to improve the quality of the paper.

\section{References}

Baguelin, F., Jezequel, J.F., Lemée, E. and LeMehaute, A. (1972), "Expansion of cylindrical probes in cohesive soils", J. Soil Mech. Found. Div. - ASCE, 98(11), 1129-1142.

Baguelin, F., Jezequel, J.F. and Shields, D.H. (1978), The pressuremeter and foundation engineering, Trans Tech Publications, Clausthall, Germany.

Carter, J.P., Randolph, M.F. and Wroth, C.P. (1979), "Stress and pore pressure changes in clay during and after the expansion of a cylindrical cavity", Int. J. Numer. Anal. Method. Geomech., 3(4), 305-322.

De Sousa Coutinho, A.G.F. (1990), "Radial expansion of cylindrical cavities in sandy soils: application to pressuremeter tests", Can. Geotech. J., 27(6), 737-748.

Gibson, R.E. and Anderson, W.F. (1961), "In-situ measurement of soil properties with the pressuremeter", Civil Eng. Public Works Rev., 56(658), 615-618.

Hill, R. (1950), The mathematical theory of plasticity, Oxford University Press, London, England.

Hill, R., Lee, E.H. and Tupper, S.J. (1947), "The theory of combined plastic and elastic deformation with particular reference to a thick tube under internal pressure", Proceedings of the Royal Society of London, Series $A$, 191(1026), 278-303.

Itasca. (1995), FLAC Version 3.3. Itasca Consulting Group, Inc., Minneapolis.

Ladanyi, B. (1972), "In-situ determination of undrained stress-strain behaviour of sensitive clays with the pressuremeter", Can. Geotech. J., 9(3), 313-319.

Mendelson, A. (1968), Plasticity: theory and application, MacMillan, New York.

Nadai, A. (1950), Theory of flow and fracture of solids, Vol.1. McGraw-Hill, New York.

Palmer, A.C. (1972), "Undrained plane-strain expansion of a cylindrical cavity in clay: a simple interpretation of the pressuremeter test", Géotechnique, 22(3), 451-457.

Perić, D. and Ayari, M.A. (2002), "On the analytical solution for the three-dimensional invariant Cam clay model", Int. J. Plasticity, 18, 1061-1082.

Randolph, M.F., Carter, J.P. and Wroth, C.P. (1979), "Driven piles in clay-the effects of installation and subsequent consolidation", Géotechnique, 24(4), 361-393.

Silvestri, V. and Abou-Samra, G. (2011), "Application of the exact constitutive relationship of modified Cam clay to the undrained expansion of a spherical cavity", Int. J. Numer. Anal. Method. Geomech., 35(1), 53-66.

Silvestri, V. and Abou-Samra, G. (2009), "Analytical solution of stress-strain relationship of modified Cam clay in undrained shear", Geomechanics \& Engineering, 1(4), 263-274.

Wood, D.M. (2007), Soil behaviour and critical state soil mechanics, Cambridge University Press, Cambridge. 
Analytical solution for undrained plane strain expansion of a cylindrical cavity in modified cam clay 37

Yu, H.S. (2000), Cavity expansion methods in geomechanics, Kluwer Academic Publishers, Dordrecht, The Netherlands.

$P L$

\section{Appendix}

Derivation of Eqs. (28a) and (28b)

Eqs. (10a) and (10b) allow determination of the shear strain increment $d \gamma=\left|d \varepsilon_{z}-d \varepsilon_{\theta}\right|$, that is,

$$
d \gamma=\frac{d \sigma_{r}{ }^{\prime}-d \sigma_{\theta}{ }^{\prime}}{2 G^{\prime}}+3 d \beta\left(S_{r}-S_{\theta}\right)
$$

But, as $d \sigma_{r}{ }^{\prime}-d \sigma_{\theta}{ }^{\prime}=2 d \tau, d \beta=\frac{d p^{\prime}}{K^{\prime} M^{2}\left(2 p^{\prime}-p_{c}{ }^{\prime}\right)}$ from Eq. (12), and $S_{r}-S_{\theta}=\sigma_{r}^{\prime}-p^{\prime}-\left(\sigma_{\theta}^{\prime}-p^{\prime}\right)=\sigma_{r}{ }^{\prime}-\sigma_{\theta}{ }^{\prime}=2 \tau$,

then Eq. (A1) becomes

a) Equation 28 a ( $G^{\prime}$ constant)

$$
d \gamma=\frac{d \tau}{G^{\prime}}-\frac{6 \tau d p^{\prime}}{K^{\prime} M^{2}\left(2 p^{\prime}-p_{c}{ }^{\prime}\right)}
$$

Since $K^{\prime}=v p^{\prime} / \kappa$, Eq. (A2) reduces to

Integration of this equation yields

$$
d \gamma=\frac{d \tau}{G^{\prime}}-\frac{6 \tau \kappa d p^{\prime}}{v p^{\prime} M^{2}\left(2 p^{\prime}-p_{c}^{\prime}\right)}
$$

$$
\gamma=\frac{\tau}{G^{\prime}}-\frac{6 \kappa}{v M^{2}} \int_{p_{i}^{\prime}}^{p^{\prime}} \frac{\tau d p^{\prime}}{p^{\prime}\left(2 p^{\prime}-p_{c}{ }^{\prime}\right)}
$$

This is Eq. (28a).

b) Equation $28 \mathrm{~b}\left(G^{\prime} / K^{\prime}\right.$ constant $)$

Since $G^{\prime}=3\left(1-2 v^{\prime}\right) K^{\prime} / 2\left(1+v^{\prime}\right)$ and $K^{\prime}=v p^{\prime} / \kappa$, Eq. (A2) reduces to

$$
d \gamma=\frac{2\left(1+v^{\prime}\right) \kappa}{3\left(1-2 v^{\prime}\right) v p^{\prime}} d \tau-\frac{6 \kappa \tau d p^{\prime}}{v p^{\prime} M^{2}\left(2 p^{\prime}-p_{c}{ }^{\prime}\right)}
$$

Integration of this equation gives

$$
\gamma=\frac{2\left(1+v^{\prime}\right) \kappa}{3\left(1-2 v^{\prime}\right) v} \int_{0}^{\tau} \frac{d \tau}{p^{\prime}}-\int_{p_{i}^{\prime}}^{p^{\prime}} \frac{\tau d p^{\prime}}{p^{\prime}\left(2 p^{\prime}-p_{c}{ }^{\prime}\right)}
$$

This is Eq. (28b). 